\title{
Managing Deviant Behavior and Resistance to Change
}

\author{
Akinlolu Ayodeji Agboola \\ Department of Management and Accounting, Obafemi Awolowo University, Nigeria \\ Tel: 234-813-112-3817Ｅ-mail: agboolaaa@yahoo.com \\ Rafiu Oyesola Salawu \\ Department of Management and Accounting, Obafemi Awolowo University, Nigeria \\ Tel: 234-803-379-5887Ｅ-mail: rsalawu@oauife.edu.ng
}

\begin{abstract}
The paper focuses on how to manage deviant behaviors and resistance to change. Case study method was used to examine practical implementation of change processes in some selected organizations.

It was discovered that change affects four basic aspects of the company: its strategy, technology, structure and employees. All these present individuals with new situations, new problems, challenges, ambiguity and uncertainty and threaten the status quo. Change influences authoritative allocation of both human and material resources and encourages competition which heats up the political climate in organizations. Resistance to change might be expressed through deviant behaviors to truncate the process or prevent implementation. The study identifies proper education, effective communication, facilitation, motivation, negotiation, manipulation, co-optation and coercion as possible methods for managing resistance to change. The use of any of these methods or combination of some, however, depends on the type of organization, nature of resistance and stage of intervention.
\end{abstract}

The paper concludes that capacity to manage deviant behavior and smoothly implement change is critical to organizational survival. Managing deviant behavior and resistance to change should be accorded strategic importance to facilitate effectiveness and efficiency in organizations.

Keywords: Change, Resistance to change, Deviant behavior

\section{Introduction}

The world today is changing at an unprecedented rate, and the environment within which organizations operate is characterized by instability resulting from increased global competition, technological innovation and change, limited resources, deregulations and privatization (Carnall 1995). Change is an unavoidable phenomenon arising from the dynamics of environment and it is inevitable for an organization that desires to grow, achieve its mission, vision and objectives. Organizations have to adapt to the environment to become competitive and stay ahead or at least keep afloat. Work processes and rules are revised, new equipments are introduced, product lines are dropped and added, and workforce is adjusted as internal and external conditions change.

Change refers to making something different from its initial position and involves confrontation with the unknown and loss of the familiar. Carr et al (2006) claim that it connotes a significant disruption in established patterns of behavior and/or expectation and could lead to discontinuity, destruction and replacement of familiar social structures and relationships. It could alter set patterns of behavior, define relationships with others, work procedures, and job skills. All these might present individuals with new situations, new problems and challenges, ambiguity and uncertainty. On an organizational level, they could lead to alteration of policies, procedures, sunk costs, organization structures, and manufacturing processes and flows (Harvey and Brown 2001). Invariably, change might affect authoritative allocation of both human and material resources and encourage competition which heats up the political climate in organizations.

The politics of change is very critical and sensitive. Because change threatens the status quo, it inherently implies political activity. New employees who have invested less in status quo and managers who are slightly removed from the main power structure might tolerate the process. However, some high up individuals in the organizations might perceive it as a threat to their skills, status, positions and behavioral patterns and construe the process as undermining their competence. Coincidentally, this latter group is a major player in change process and capable of manifesting behavior of resistance. 
Proposing a change in an organization can affect several aspects beyond the initial conception. Change in structure may affect the culture of the organization as well as the attitude that individuals have towards work. New structures mean new reporting relationships, new tasks and job descriptions for employees. All these may trigger resistance from those who feel disadvantaged by the new arrangement. The multi-dimensional nature of the effects of change poses challenges to managers and calls for effective management in its implementation.

The manager could change four basic aspects of the company: its strategy, technology, structure and employees (Desler 2007). Strategic change affects the way the company creates and markets its products or services. It covers the purpose and mission of the organization, its corporate philosophy on such matters as growth, quality, innovation and values concerning employees and customers, competitive positioning and strategic goals for achieving and maintaining competitive advantage and for product-market development (Armstrong, 2009) Structural change focuses on reorganizing the chart and structural elements of the firm. This may involve replacing, dismissing or adding personnel. Technological changes are mostly concerned with automation of processes. Influences of information and communications technology have made this change not only desirable but also an on-going process as the dynamism of technology continues to dictate the competitive strength of business organizations. Employees may be changed through learning activities such as training, education and development programs. They need new orientation to ensure that the organization keeps pace with changes in the environment.

The principal models of change management stem from the work of Kurt Lewin in the 1940's who developed the planned approach to change. Graetz et al (2006) states that Lewin's approach to organizational change is grounded in a general system of ideas termed 'field theory'. This theory stipulates that organizations are constantly exposed to two forces of those that maintain stability and those that break it down. The normal state for organizations is one of equilibrium in which the forces for stability are dominant. To achieve change, the organization would need to reduce the forces for stability or increase the forces for change. Lewin's change model involves three steps: unfreezing, moving and refreezing.

Unfreezing contains a reduction in the field forces that maintain an existing organizational culture and method of operations. It involves breaking psychological attachment to the past by using information that demonstrates the existence of problems (Graetz et al 2006). The principle is that the equilibrium needs to be destabilized (unfrozen) before old behavior can be discarded (unlearnt) and new behavior can be successfully adopted. Burnes (2004) expands on Lewin's ideas and explains that the key to unfreezing is to recognize that change, whether at the individual or group level is a profound psychological dynamic process.

The second stage is moving which entails the creation of cognitive recognition in the workplace of the need for change, and the establishment of new norms of behavior around a particular set of new structures and processes (Graetz et al 2006). Essentially this means moving from a less acceptable to a more acceptable set of behaviors.

The third level, refreezing, basically involves cultural reinforcement of the new learnt behaviors. The focus of refreezing is to ensure that the new behaviors are to some degree, congruent with the rest of the behavior, personality and environment of the learner in order not to lead to a new round of disconfirmation (Burnes, 2004). It is implied here that Lewin saw successful change as a group activity because unless group norms and routines are transformed, changes in individual's behavior will not be sustained (Graetz 2006). It is pertinent to note that the concept of refreezing might not apply to many modern day organizations that are encouraged to thrive on chaos and constant change. Thriving resonates with actual experiences because the period of time between phases of planned change had dwindled to zero. Current managers have to deal with a much more turbulent environment that is full of uncertainties and face constant change bordering on chaos. Managers need to make prudent organizational change decisions by envisaging how employees are likely to react to them. Implementation of change is an interplay between change paths and change planning tools. The paths are the products of a particular blend of personal, cultural, organizational and environmental characteristics that make each organization's experience of change different.

\section{Resistance to Change}

The significance of the degree of change is measured mainly by how those affected perceive and react to it (Carr et al 2006). Organizational change involves moving from known to unknown. Because the future is uncertain and may adversely affect people's competencies, worth and abilities, organizations' members generally do not support change unless compelling reasons convince them to do so. Any change will result in responses from those that might be affected positively or negatively. Perceived positive effect of change will promote commitment while negative perception will generate resistance. 
Judson (1991) identifies a spectrum of possible behaviors towards change as acceptance; indifference; passive resistance; and active resistance. Resistance to change may be expressed through deviant behaviors to truncate the process or prevent implementation. Because deviant behavior and delinquency could produce organizational losses, managing deviant behavior and resistance to change is crucial to every organization and must be accorded strategic importance. Goetsch and Davis (2006) allude to the fact that the capacity to manage resistance and smoothly implement change to meet environmental challenges is essential to organizational survival.

Resistance to change is mainly an effort to maintain the status quo (Carr et al 2006). It is a behavior put up to protect an individual from the perceived effects of real or imagined threat. Gaetz et al (2006) describe resistance to change as barriers arising from organizational politics, inappropriate use of power, challenges to cultural norms and institutionalized practices, lack of understanding, inappropriate timing, inadequate resources, incorrect information or employee suspicion of honorable management intentions. Harvey and Brown (2001) contend that resistance to change is usually a reaction to methods used in implementing a change rather than any inherent human characteristics. They claim that people tend to resist changes that do not make sense to them or that are forced on them against their will.

Resistance does not necessarily surface in standardized ways. It can be overt, implicit, immediate or deferred (Robbins 1996; Nadler 1998). Whichever form it takes, it is usually viewed as a negative force, especially by the management because it can occur irrespective of the value of the change effort proposed. Graetz et al (2006) however, contend that resistance to change can also serve positive purposes such as firing change initiators to reconsider hasty plans or marshalling employees' support for new vision. They put forward four schools of thought to explain why employees resist change. They include Psychological, Systems, Institutional and cultural models of resistance to change

The Psychological Model of Resistance claims that individuals by nature challenge any type of change. The central idea here is that sources of resistance to change reside in basic human characteristics, such as perceptions, personalities, and needs. The notion of dramatic change for most people is downright scary and the natural response is resistance. Typical causes of this include uncertainty, lack of tolerance, differences in opinion concerning the need for change and threatened self-importance.

Systems Model of Resistance views resistance to change as a system concept that reflects organizational members' discomfort with the process modifications that are likely to disadvantage them. This implies that what people resist is not change per se but loosing something they like, such us status, money or comfort.

Institutionalized Resistance to change focuses on behaviors that have become embedded in an organization's legitimate structures, decision making processes and resources allocation (Graetz 2006). Organizations by their very nature are conservative and actively resist change. This model therefore explains the resistance of organizational members to change that they perceive as unnecessary.

Organization's Culture is a pattern of beliefs and expectations that are common to members of a social unit and subsequently set the behavioral standards or norms for all new employees. Because culture is intrinsically inflexible, determined and shared by members of an organization, and has profound influence on behavior, any attempt to change its core assumptions might be met with resistance.

While these categories are desirable for theoretical construct, the clear cut distinctions between them may not appropriate reality. For instance, sources of resistance between individual and organizations overlap in the real world. Graetz et al (2006) argue that resistance is found within the constructed realities that individuals operate within. They criticize the modernist perspective that presumes all people share a reality and therefore view a change initiative in the same ways. Managing resistance therefore requires bringing these background conversations into the foreground to examine and work through them.

\subsection{Deviant Behaviors}

Deviant behavior is only one of many forms of resistance. Judson (1991) argues that the form any resistance takes depends on individual's personality, the nature of the change itself, attitudes towards it, forces driving it from the group and the organization and its environmental context. According to him, deviant behaviors are all types of oppositions that are aggressive or hostile manifestations of resistance to change. They are actions which transgress commonly held norms. What is regarded as deviant can shift from time to time and place to place; normal behavior in one cultural setting may be labeled deviant in another (Giddens 2000). In essence, it is a behavioral departure from norms of a reference group (Warren, 2003). Wilmot shares this sentiment that deviant behavior has to do with transgressions from common societal or organizational norms. A person would be considered to be acting defiantly if he violates the significant social norm in that particular culture. 
Notable deviant behaviors in the workplace include absenteeism, striking, sabotage, gossip and physical violence. Werner and De Simone (2008) create typology of deviant workplace behaviors and categorized-them into four. They include production deviance (leaving early or intentionally working slowly); property deviance (sabotaging equipment, lying about hours worked); political deviance (showing favoritism, seeming or gossiping about co-worker; personal aggressions (sexual harassment, verbal abuse, endangering or staling from co-workers). Deviant behavior may also include acts that are interpersonal in nature, like sexual harassment, aggression towards co-workers, verbal abuse, physical assault and political behaviors. Managers' attention should not only focus on the physical deviance directed towards the organization but also take cognizance of those directed at individuals. Lawrence and Robinson (2007) reflect this when they describe workplace deviance as voluntary behavior that violates significant organizational norms and perceived it as threatening the well-being of the organization or its members. It is caused by provocations arising from perceived disparities between a current state and some ideal state, need, and desire which create frustration. This frustration motivates deviant behavior that is either instrumental or expressive in nature.

Although deviance may be dysfunctional and threatening to the well-being of an organization or individual, a lot of positive outcomes can also emanate from it. It can alert group members of their common interest and provide warning signals to the organization as a whole. Interpersonal deviance may serve positive social functions by assisting to build group cohesion.

\subsection{Change Management Interventions}

Behavior modification means changing or modifying behavior through the use of contingent rewards or punishment. It assumes, for instance that behavior that appears to lead to a positive consequence or reward tends to be repeated, while behavior that leads to negative consequence or punishment tends not to be repeated (Desler, 2007). Management must be able to spot resistance early to be able to respond before it takes hold. It must be on the lookout for undesirable behaviors. Mooketsi (2009) suggests the following methods for overcoming resistance to change:

i. Education and Communication: This method could be used when resistance is noted to have arisen from lack of information and analysis. Effective use of the method may encourage the employees to help in the implementation of change.

ii. Foster Open Communication: Employees usually have a lot of questions that need clarification. Subordinates and Management should be able to converse together. Open communication minimizes speculations, wrong perceptions and rumors.

iii. Participation and Involvement: This approach is useful to buy employees in into the change process. People who participate in fostering a change will be committed to its implementation. Formidable resistance is unlikely to come from employees that took part in the process. Useful information is usually provided that will be integrated to improve and ease the process of implementation of desired change.

iv. Facilitation and Support: This may be useful when employees are resisting because of adjustment problems. Management should guide them to ease the transition.

v. Negotiation and Agreement: This is desirable when dealing with unions and any group that has power to influence.

vi. Manipulation and Co-optation: This can be used when other methods have failed or expensive.

vii. Implicit and Explicit Coercion: This may be used when there is time constraint. When the change must be implemented within a short period of time to save the organization

The role of management is crucial in every change process. Management is the art of getting things done through people in organizations (Hill and McShame, 2008). Managers are to give organizations a sense of purpose and direction; they can motivate ordinary people to do extra-ordinary things. Effective managers should be capable of relating individuals, groups, and formal structures to the needs of the organization. Dube (2009) suggests that managers could utilize the following to ensure smooth change process:

i. Perception: Managers should be able to interpret sensory inputs effectively and ensure that employees perceive the organizations objective correctly. They need to understand workers grievances and complaints and empathize with problems confronting various departments. It is necessary to facilitate good communication between managers and subordinates.

ii. Learning: Individuals in the organizations should be encouraged to acquire new knowledge, skill and attitude. Learning helps people to understand better and influences behavior. 
iii. Motivation: this focuses on the totality of individual's dispositions and motives to behave in a certain way. Managers should endeavor to know the drives and forces that can influence employees' behavior. Employees are motivated partly by the need to earn a living and also by human needs for job satisfaction and security of tenure. All these should be factored into the process of change.

iv. Support is very essential for effecting a smooth change. People undergoing change need material, moral and emotional support. Undergoing change is a lot like walking a tightrope for the first time. It will go smoothly if you have someone to help you get started, someone waiting at the other end to encourage progress, and a safety net underneath in case you fall (Goetsch and Davis, 2006).

People are primary inhibitors of change in organizations and it is important to pay attention to them. Managers should listen to hear what is being said and observe what is not being said. Employees who are listened to and heard are likely to participate more in change process than those who are not. Everyone who is affected by change should be involved in making it happen. It can be difficult when people feel that change is being imposed on them. Employees should therefore be involved in planning and implementing change. They should be given opportunity to express their concerns and fears. Getting problems into the open from the onset would allow them to be dealt with while shoving them aside or ignoring them will transform little problems into big ones.

\section{Case Study 1: Stoppage of Automatic Salary Increments}

The company had an established tradition of automatic salary increment on yearly basis to take care of inflation. A new change that removed this privilege was introduced in 2009. The announcement of this change came as a rude shock to the employees. The situation was worsened by the fact that management did not prepare the employees in any way for a soft landing. No compensation or any other alternative to cushion the effects of the cancellation.

The employees felt cheated about the management decision. There was a feeling of uncertainty among the employees regarding the direction towards which the company was heading. Many believed that no increments could eventually lead to a cancellation of the annual bonuses, or worse still, retrenchment. Employees were sitting and chatting in small groups all the time, discussing the issue of no increments. They were making statements like "why should I go all out for the company that doesn't really appreciate what I do for it?"

A number of deviant behaviors were noticed. Some employees became hostile and displayed undesirable team member behaviors. They became slack in their duties leading to a drastic drop in productivity as indicated by the companies' scorecard. A drop of 4\% was noticed at the end of January and 5\%n in February. Some employees revealed company's sensitive information such as pricing lists/tariff, top customer information and marketing strategies to the competitors. Anonymous tip-offs to management revealed that some were planning to go on strike and boycott duties. Theft incidents ranging from couriers rolling over money to stealing actual shipments of valuables like phones, laptops iPods were reported. Siphoning of fuel from company vehicles, obtaining company fuel by unauthorized means, stealing and using customer's credit cards were other forms of stealing noticed. The Human Resources department noticed an increased number of employees on sick leave and a strong desire by some employees to leave the company.

An emergency staff meeting was convened by the management to address the issues. Power coercive was first employed because of time constraint to prevent the intended industrial action. Disciplinary actions were taken against the concerned staff. Some were dismissed while others received warning letters. An interactive initiative, 'First Choice', aimed at improving morale of workers was thereafter put in place as a long run solution. All employees in the company were to nominate members of staff that achieved extraordinary results monthly. The selected employees were given various gifts such as digital cameras, Plasma TV screen and shopping vouchers. At the end of the year in November the best three out of the monthly winners would be chosen and offered an all-expense paid trip to Mauritius for a week. This initiative helped to mitigate the effect of the change introduced. Morale of workers improved, negative behavior decreased and performance began to improve.

\section{Case Study 2: Introduction of performance-based rewards.}

At the end of the year, employees were automatically offered a $13^{\text {th }}$ check, an additional $100 \%$ of their monthly salary. Towards the end of the year in 2007 management decided to change the bonus structure to a performance based one and linked it to employees IKOs (Individual Key Objectives). The new policy was based on the annual appraisals.

The employees questioned the modus operandi of the new policy. Attaching payment of the bonus to the IKOs towards the end of the year was like changing the rule in the middle of the game. They thought that the 
management was devising methods of reducing their bonus or not paying it at all. Many employees felt the change was introduced to suit the company, and that their rights were being trampled upon.

The employees became very uncooperative and made the annual appraisal process difficult to implement. A petition was written to the management stating that the company treated them with disrespect because they were never consulted before introducing a change that affected them that much.

Management decided to use consultation and education to address the resistance. A meeting was held with the functional leaders of the employees to intimate them with the major attractions of the new policy. They explained that the employees could gain more from the new scheme that is more flexible and attached to performance. It was also agreed that the implementation of the new policy would not take effect until the following year. The HODs (Heads of Department) were tasked with the responsibility of relaying the information to their respective departments and educate them on the benefits of the new bonus structure. Eventually, employees welcomed the new bonus structure and were inspired to work harder to use the advantage of its flexibility to gain more at the end of the year. This method of resolution agrees with Burnes (2004) who emphasizes the importance of the learning process in implementing successful change. It allows those involved to gain or change insights, outlooks, expectations and thought patterns. The approach uses consultation and education to overcome resistance and provide change adopters with an opportunity to mutually agree on amicable resolution of conflict.

\section{Case Study 3: Mining Company}

A diamond mining company partly owned by the government and a private company has been in operation since 1966. The mandate of the company is to mine diamonds and also contribute to the development of areas and surrounding various mines locations. The current global recession has adversely affected the company and forced it to resort to extreme cost cutting measures. The first change introduced was the centralization of some critical functions through the establishment of the 'Shared Services Office'. The new office took over the functions of accounts and payroll. Management also decided to outsource functions like shops and the maintenance department. Centralization and outsourcing meant that certain posts would become redundant and resulted in retrenchment. Management also closed down some operations for a couple of months. There was uncertainty as to whether some of the mining plants would resume operations in the near future. Morale in the company became low with a lot of uncertainty over employee's future.

Employees were very upset because they were neither informed nor involved in the process of the emergent change. Tempers flared up and most people boycotted their duties and demonstrated to express their resistance and frustrations. The mines experienced huge losses in terms of revenue for the lost man-hours. Given the sensitive and unpredictable nature of the issue, and the perceived insecurity of tenure, quite a number of employees decided to seek alternative employment. Among those affected were key players who ended up leaving expensive projects half way in search of more stable working conditions. Such projects were eventually abandoned due to lack of skilled manpower. The company lost a lot of money and time invested in these projects.

The management decided to engage the mining union in extensive discussions. New salary packages were rolled out to motivate workers. Management explained to the employees that the closure of the company was a cost-saving exercise. They assured that all the employees would be on full pay during the temporary closure of the mine and that salary cuts and further retrenchment would stop. All these assisted to pacify the workers and created a positive working environment in the company.

The above three cases show a general trend of a top down approach to introducing and implementing change. The general assumption was that employees would embrace whatever change introduced in the organization with little or no resistance. This assumption did not appropriate reality. Employees are more likely to accept change if they are well informed and involved. Educating and involving employees in planning and implementing change is vital to its success. As seen in the cases, employees became more understanding and receptive of the changes after management intentions and reasons for introducing the change were properly explained to them, even when the negative impact had not been fully removed. Organizations should allow employees to be part of the change process. Management needs to see employees as partners who can assist to facilitate the change process in a smooth manner and educate them on how it could affect them. The reasons for the change should be well communicated and efforts should be made to mitigate its impact to avoid loss of productivity and decreased performance. 


\section{Conclusion}

Change has become an inevitable phenomenon in the present age of global competition and dynamic business environment. It is not only desirable but necessary to create a vision of change and communicate same to all the stakeholders. Successful change depends on proper integration of human resource management policies with strategies. These policies have become critical facilitators in the process of change and often determine employees' commitment and how they relate with the nature and direction of the firm. Policies on training, education, compensations, security of tenure of office are particularly critical to the smooth implementation of change. These policies should be handled by committed and visionary leadership who properly understand the firm's culture. To ensure smooth implementation, proper explanation for the need for change must be provided and the interests of those that might be affected should be protected.

\section{References}

Armstrong, M. (2009). Armstrong's Handbook of Human Resource Management Practice, (11 ${ }^{\text {th }}$ ed.) Kogan Page, London

Burnes, B. (2004). Managing change, (4 ${ }^{\text {th }}$ ed.). Essex: Pearson Education Limited.

Carnall, C. A. (1995). Managing change in Organizations. ( $2^{\text {nd }}$ ed.). Hertfordshire: Prentice Hall International.

Carr, D. K, Hard, H J., \& Trahant, W J. (1996). Managing the Change process: A Field Book for Change Agents, Consultants, Team Leaders, and Reengineering Managers. New York: McGraw-Hill.

Desler, G. (2007). Management Principle and Practices for tomorrow's Leaders. (3 $\left.{ }^{\text {rd }} \mathrm{ed}\right)$. United States of America: Haughton Mifflin.

Dube Like. (2009). Managing Deviant Behavior and Resistance to change in Selected Organizations, Unpublished Assignment Submitted to the Department of Management, Faculty of Business, University of Botswana, as Part of Assessment for MGT 674

Giddens, A. (2000). Sociology: A new Introduction. ( $3^{\text {rd }}$ ed.), United Kingdom: Polity Press, Oxford.

Goetsch, D., \& Davis S. B. (2006). Quality Management: Introduction to Total Quality Management for Production, Processing and Services. New Jersey: Pearson Prentice Hall.

Graetz, F., Rimmer, M., Lawrence, A., and Smith, A. (2006). Managing Organizational Change. (2 ${ }^{\text {nd }}$ ed.). Australa: Wiley and Sons, Sidney and Melbourne.

Harvey, D., \& Brown D. R. (2001). An Experiential Approach to Organization Development. (6 ${ }^{\text {th }}$ ed). New Jersey: Pearson Prentice Hall.

Judson, A. S. (1991). Changing Behavior in Organizations. Massachusetts and Oxford: Basil Blackwell inc.

Lawrence T. B., \& Robinson, S., L. (2007). Ain't Misbehaving Workplace Deviance as Organizations Resistance. Journal of Management, 33, 378-394

Mooketsi, D. S. (2009). Managing Deviant Behavior and Resistance to Change, Unpublished Assignment Submitted to the Department of Management, Faculty of Business, University of Botswana, as Part of Assessment for MGT 674.

Warren D. E. (2003). Constructive and Destructive Deviance in Organizations. Journal of Academy of Management Review, 28, 622-632.

Werner, J. M., \& DeSimone, R. L. (2008). Human Resource Development, (5 ${ }^{\text {th }}$ ed.). South Western, Mason. 
Table 1. Case Studies on Management of Change

\begin{tabular}{l|l|l|l|l|l}
\hline Cases & $\begin{array}{l}\text { Change } \\
\text { Introduced }\end{array}$ & $\begin{array}{l}\text { Defects in } \\
\text { Methods }\end{array}$ & Perceived Effects & Deviant Behaviors & $\begin{array}{l}\text { Response of } \\
\text { Management }\end{array}$ \\
\hline $\mathbf{1}$ & $\begin{array}{l}\text { Stoppage of } \\
\text { automatic annual } \\
\text { salary increment }\end{array}$ & $\begin{array}{l}\text { a. No adequate } \\
\text { notice } \\
\text { b. No cushion } \\
\text { effect } \\
\text { c. } \\
\text { Non-involvement } \\
\text { of employees }\end{array}$ & $\begin{array}{l}\text { a. Feeling cheated } \\
\text { b. Fear of further } \\
\text { punitive measures } \\
\text { like retrenchment } \\
\text { c. No increment may } \\
\text { lead to no bonus }\end{array}$ & $\begin{array}{l}\text { a. Hostility and } \\
\text { undesirable behavior } \\
\text { b. Sabotage } \\
\text { c. Planning to go on } \\
\text { strike } \\
\text { d. Pretence and false } \\
\text { sick leave }\end{array}$ & $\begin{array}{l}\text { a. Coercion to prevent } \\
\text { strike-warning letter } \\
\text { and dismissal } \\
\text { b. Introduction of } \\
\text { 'First Choice'- } \\
\text { compensation for the } \\
\text { best worker to } \\
\text { motivate them. }\end{array}$ \\
\hline $\mathbf{2}$ & $\begin{array}{l}\text { Changing of bonus } \\
\text { structure to } \\
\text { performance-based } \\
\text { reward linked with } \\
\begin{array}{l}\text { IKO (individual } \\
\text { key objective) }\end{array}\end{array}$ & $\begin{array}{l}\text { a. No consultation } \\
\text { not properly } \\
\text { educated on the } \\
\text { need for change }\end{array}$ & $\begin{array}{l}\text { a. Wrong modus } \\
\text { operandi } \\
\text { b. Perceived denial of } \\
\text { rights } \\
\text { c. Fear of reduction in } \\
\text { bonuses }\end{array}$ & $\begin{array}{l}\text { Employees became } \\
\text { uncooperative. }\end{array}$ & $\begin{array}{l}\text { a. Consultation by } \\
\text { organizing a meeting } \\
\text { with employees } \\
\text { b. Education on the } \\
\text { attractions of the new } \\
\text { change } \\
\text { c. Motivation through } \\
\text { reward system }\end{array}$ \\
\hline $\mathbf{3}$ & $\begin{array}{l}\text { Centralization of } \\
\text { crucial services } \\
\text { and closure of } \\
\text { some operations }\end{array}$ & $\begin{array}{l}\text { Employees were } \\
\text { neither given } \\
\text { prior information } \\
\text { nor involved in } \\
\text { the process }\end{array}$ & $\begin{array}{l}\text { a.Certain posts became } \\
\text { redundant } \\
\text {. Perceived insecurity } \\
\text { of tenure and possible } \\
\text { retrenchment }\end{array}$ & $\begin{array}{l}\text { a. Boycott of duties } \\
\text { b. Change of }\end{array}$ & $\begin{array}{l}\text { a. Discussion } \\
\text { b. Improved }\end{array}$ \\
\hline
\end{tabular}

